\title{
PERDA DE PRODUTIVIDADE EM FUNÇÃO DA DESSECAÇÃO ANTECIPADA DA SOJA TRANSGÊNICA
}

\author{
Tiago Roque Benetoli da Silva', Gustavo Fassini²
}

'Eng. Agrônomo Dr. Faculdade Assis Gurgacz - FAG, Curso de Agronomia. Avenida das Torres n. 500, CEP: 85.806-095, Bairro Santa Cruz, Cascavel, PR. E-mail: benetoli@fag.edu.br.

${ }^{2}$ Engenheiro Agrônomo - Universidade Católica Dom Bosco, Centro de Pesquisa São Vicente, Av. Tamandaré 8001, Bairro Lagoa da Cruz., CEP 79117-900 Campo Grande, MS. E-mail: gustavo_fassini@hotmail.com

\section{RESUMO}

O presente trabalho foi realizado na Fazenda Campo Verde, no município de São Gabriel do Oeste - MS, com o objetivo avaliar a perda na produtividade da soja transgênica, em função da antecipação da dessecação. O delineamento experimental foi o de blocos casualizados, com quatro repetições. As parcelas foram constituídas por diferentes períodos de dessecação da soja antes da colheita prevista $(5,10,15,20$ dias antes da colheita e sem dessecação). A semeadura da soja (BRS Valiosa RR) foi realizada em três de novembro de 2005 e, cada parcela experimental foi composta por 6 linhas de $5 \mathrm{~m}$ de comprimento, considerando como área útil as 4 linhas centrais, desprezando-se $0,5 \mathrm{~m}$ das extremidade de cada linha. Foram realizadas as seguintes avaliações: população final de plantas, componentes da produção, massa de 100 grãos, umidade nos grãos e produtividade. De acordo com os resultados obtidos, pode-se concluir que a aplicação de dessecantes deve ser realizada no máximo 6 dias antes da colheita, para não causar redução na produtividade de grãos.

Palavras-chave: Herbicida, Glycine max, umidade de grãos, colheita

\section{LOSS YIELD ON PREVIOUSLY DESICCATION OF TRANSGENIC SOYBEAN}

\begin{abstract}
The experiment was conducted in Campo Verde farm, São Gabriel do Oeste, Mato Grosso do Sul state, Brazil. The objective was to evaluate the loss yield of transgenic soybean previously desiccated. The experimental design was randomized blocks, constituted by different desiccation periods $(5,10,15$ and 20 days before harvest and no desiccation), with four replications. The soybean (BRS Valiosa RR) was sowed on November $3^{\text {rd }} 2005$ and the experimental plot was 6 five meter lines, considering the 4 central lines as the studied area. The following parameters were evaluated: final plant stand, production component, mass of 100 grains, grain humidity and yield. The data indicated that the desiccation must be done 6 days before harvesting to prevent reduction in grain yield.
\end{abstract}

Key words: Herbicide, Glycine max, grain humidity, harvest 


\section{INTRODUÇÃO}

Os herbicidas dessecantes podem ser usados visando a dessecação em lavouras em final de ciclo, com a finalidade de controlar plantas daninhas e provocar a desfolha da cultura. $\mathrm{O}$ procedimento facilita o trabalho das colhedeiras e permite a antecipação da colheita, com redução dos prejuízos decorrentes de fungos e pragas que incidam sobre a cultura no final do ciclo (Lacerda et al., 2005).

O ponto considerado de colheita da soja é o estádio reprodutivo $\mathrm{R} 8$, porém, antes desta fase, a soja atinge sua maturação fisiológica no estádio reprodutivo R7. Nesta fase as sementes apresentam máximo vigor e germinação, entretanto, o teor de umidade das sementes é aproximadamente de 50 a $60 \%$ o que torna inviável a operação de colheita das sementes, devido aos danos físicos nas sementes e à grande quantidade de folhas que impossibilitam a colheita mecânica. Para contornar esses problemas a utilização da dessecação química é a uma das formas encontradas por alguns produtores. Esses produtos químicos têm por características desidratar as sementes e promover antecipação da colheita de soja sem alterar a produção por período máximo de sete dias (Arantes e Miranda, 1993; Lacerda et al., 2001).

Em trabalho realizado por Lazarini et a1. (1999), com a aplicação de dessecantes, antecipou-se a colheita de soja em nove dias, em relação à época normal, havendo redução no teor de água da semente de 30 para $17 \%$, no período de 3 a 5 dias após aplicação; em dois anos de pesquisa, na lavoura onde se aplicou o dessecante paraquat obteve-se alguma superioridade na qualidade das sementes, e no último ano de pesquisa não houve grande benefício à germinação e ao vigor. Por outro lado, alguns dessecantes podem deixar resíduos, causando redução no vigor das sementes, ou então, promover rápido desenvolvimento de fungos nas hastes, vagens e sementes, estando esses riscos relacionados às condições ambientais na época da aplicação.

Lacerda et al. (2005), em trabalho objetivando verificar a melhor época de aplicação de dessecantes, a fim de permitir a colheita de sementes de soja com a máxima qualidade fisiológica e sanitária, concluíram que nas condições ambientais em que se realizou a pesquisa, a melhor época de dessecação foi quando as plantas estavam com 80 a $90 \%$ de vagens com coloração amarela e marrom e teores de água nas sementes entre 45 e $60 \%$.

O objetivo deste trabalho foi avaliar a perda na produtividade da soja transgênica, em função da antecipação da dessecação.

\section{MATERIAL E MÉTODOS}

$\mathrm{O}$ experimento foi conduzido na Fazenda Campo Verde, no município de São Gabriel do Oeste, MS, entre as coordenadas geográficas de latitude $19^{\circ} 20^{\prime} 00^{\prime \prime}$ sul e longitude $54^{\circ} 39^{\prime} 00^{\prime \prime}$ oeste.

O delineamento experimental foi o de blocos casualizados, com quatro repetições. As parcelas foram constituídas por diferentes períodos de dessecação da soja antes da colheita $(5,10,15,20$ dias antes da colheita e sem dessecação).

A área experimental estava localizada em um solo classificado como LATOSSOLO VERMELHO (EMBRAPA, 1999). A análise química do solo $(0-20 \mathrm{~cm})$ apresentou $8,8 \mathrm{mg} \mathrm{dm}^{-3}$ de fósforo (Mehlich 1); 38,5 $\mathrm{g} \mathrm{dm}^{3} \mathrm{de} \mathrm{MO} ; 5,0 \mathrm{pH}$ em $\mathrm{CaCl}_{2} ; 3,0$; $32 ; 12 ; 52$ e $99 \mathrm{mmol}_{\mathrm{c}} \mathrm{dm}^{-3}$ de $\mathrm{K}, \mathrm{Ca}, \mathrm{Mg}$, $\mathrm{H}+\mathrm{Al}, \mathrm{SB}, \mathrm{CTC}$ respectivamente e $\mathrm{V} \%=48$. Anterior ao cultivo do experimento, a área encontrava-se cultivada com milheto.

A variedade de soja utilizada foi a BRS Valiosa RR (modificação genética da variedade Conquista), com período juvenil longo, ciclo semi-precoce a médio (EMBRAPA, 2005). 
A semeadura foi realizada em 3 de novembro de 2005 com adubação constituída de $320 \mathrm{~kg} \mathrm{ha}^{-1}$ do fertilizante 2 23-23 + boro e zinco, baseando-se na análise química do solo e as recomendações de Ambrosano et al. (1997). Cada parcela experimental foi composta por 6 linhas de 5 $\mathrm{m}$ de comprimento, espaçadas entre si por $0,45 \mathrm{~m}$. Considerou-se como área útil as 4 linhas centrais, desprezando-se $0,5 \mathrm{~m}$ de ambas as extremidades.

As sementes foram tratadas com inseticida aldoxicarb (40 g do i.a./100 kg de sementes) e com methyl benzimidazol + tetramethylthiuram disulfide $(30 \mathrm{~g}+70 \mathrm{~g}$ do i.a. $/ 100 \mathrm{~kg}$ de sementes) e 300 gramas de inoculante para $50 \mathrm{~kg}$ de sementes.

A emergência ocorreu em 8 de novembro de 2005. Os demais tratos culturais e fitossanitários foram os normalmente recomendados à cultura da soja para a região. Foram realizadas duas aplicações de metamidofós na dose de $0,8 \mathrm{~L}$ i.a. $\mathrm{ha}^{-1}$, duas aplicações de fungicida flutriafol na dose de $80 \mathrm{~g}$ i.a. ha ${ }^{-1}$ e uma aplicação de epoxiconazole + pyraclostrobin $\left(25 \mathrm{~g}+67 \mathrm{~g}\right.$ do i.a. $\left.\mathrm{ha}^{-1}\right)$.

$O$ controle de plantas daninhas foi realizado através do monitoramento da cultura, utilizando aplicação de herbicida glifosate na dose de $960 \mathrm{~g}$ i.a. ha ${ }^{-1}$

A aplicação dos tratamentos iniciouse quando a cultura se encontrava o estádio $\mathrm{V} 7$, com o produto paraquat + diuron na dosagem de $500 \mathrm{ml}$ do i.a. ha ${ }^{-1}$. As aplicações foram realizadas com pulverizador costal, em jato dirigido às plantas, nos períodos de 5, 10, 15 e 20 dias antes da colheita, com tratamento testemunha (sem aplicação de dessecante). A colheita foi realizada em todas as parcelas em 19 de março de 2006, totalizando ciclo de 136 dias. avaliações:

Foram realizadas as seguintes

Por ocasião da colheita, foram coletadas 10 plantas em local pré- determinado, na área útil de cada parcela e levadas para o laboratório para determinação do número de vagens por planta, grãos por planta e grãos por vagem.

Foram coletados os grãos após a colheita, representados por uma pequena amostra de cada parcela, pesados e colocados para secagem em estufa de ventilação forçada de ar a $60-70^{\circ} \mathrm{C}$, por 120 horas. A seguir, foram pesados novamente obtendo-se assim o teor de umidade existente nos grãos.

Por ocasião da colheita, foi avaliada a população de plantas através da contagem das plantas da área útil das parcelas.

A massa de 100 grãos foi obtida através da coleta ao acaso e pesagem de duas amostras por parcela.

As plantas da área útil de cada parcela foram arrancadas e deixadas para secar a pleno sol. Após a secagem, as mesmas foram submetidas à trilhagem manual, os grãos foram pesados e os dados transformados em $\mathrm{kg} \mathrm{ha}^{-1}$ (13\% base úmida), obtendo-se assim a produtividade.

Foi realizada análise de variância (teste F) para todos os dados e, em caso de significância a $5 \%$ de probabilidade, foi procedida análise de regressão polinomial, optando-se pela equação significativa. Tanto na regressão linear quanto na quadrática, foi utilizada a equação com maior coeficiente de ajuste $\left(\mathrm{R}^{2}\right)$.

\section{RESULTADOS E DISCUSSÃO}

O número de grãos por planta, grãos por vagem, vagem por planta e umidade, não sofreram influência dos tratamentos (Tabela 1), ou seja, a aplicação de dessecante em várias épocas não causou alteração nestes parâmetros. Alguns trabalhos envolvendo épocas de aplicação de dessecante em feijão e soja também não foram observados diferenças no número de grãos por planta $\mathrm{e}$ grãos por vagem (Silva et al., 1999; Miguel, 2003; Silva et al., 2006). 
Silva et al. (2006), trabalhando com dessecação em pré-colheita em soja na região de Viçosa (MG), observaram diferenças no número de vagens por planta e teor de umidade nos grãos, em função do aumento do intervalo entre a aplicação e a colheita, mostrando que a planta ainda estava em atividade metabólica em épocas mais distantes da colheita.

Tabela 1. Grãos por planta e por vagem, vagem por planta e umidade em função da aplicação de dessecante antes da colheita. São Gabriel do Oeste (MS) - 2006.

\begin{tabular}{|c|c|c|c|c|}
\hline Tratamentos & Grãos por planta & Grãos por vagem & Vagem por planta & Umidade \\
\hline Dias antecedentes à colheita & -------- & -------número----- & - & $---\%$ \\
\hline 0 & 74,2 & 2,1 & 35,3 & 6,0 \\
\hline 5 & 61,8 & 2,0 & 29,4 & 6,2 \\
\hline 10 & 73,9 & 2,0 & 36,1 & 5,9 \\
\hline 15 & 80,8 & 2,1 & 37,4 & 6,0 \\
\hline 20 & 70,8 & 2,1 & 33,7 & 5,9 \\
\hline $\mathrm{CV} \%$ & 12,3 & 2,9 & 10,4 & 3,7 \\
\hline $\mathrm{F}$ tratamentos & n.s. & n.s. & n.s. & n.s. \\
\hline R.L. & n.s. & n.s. & n.s. & n.s. \\
\hline R.Q. & n.s & n.s. & n.s. & n.s. \\
\hline
\end{tabular}

n.s. = não significativo

R.L. = regressão linear

R.Q. = regressão quadrática

Miguel (2003) trabalhando com aplicação de dessecantes em feijoeiro na região de Piracicaba (SP) também não observou diferença no teor de umidade das sementes em função dos tratamentos. Lacerda et al. (2003) observaram que após sete dias da aplicação de dessecantes o teor de água nos grãos de soja cai bruscamente, chegando em média a $9,0 \%$ de umidade, porém depois não diminui mais, não havendo diferença na época de aplicação.

Observa-se que a população final de plantas não foi influenciada pelos tratamentos (Tabela 2).

Tabela 2. População final de plantas, massa de 100 grãos e produtividade em função da aplicação de dessecante antes da colheita. São Gabriel do Oeste (MS) - 2006.

\begin{tabular}{cccc}
\hline Tratamentos & População final & Massa de 100 grãos & Produtividade \\
\hline Dias antecedentes à colheita & plantas.ha ${ }^{-1}$ & ----- g----- & - kg.ha $^{-1}--$ \\
0 & 309.259 & 17,3 & 3.633 \\
5 & 314.814 & 17,7 & 3.749 \\
10 & 312.963 & 17,9 & 3.354 \\
15 & 315.444 & 17,1 & 3.234 \\
20 & 309.259 & 15,4 & 3.026 \\
\hline CV $\%$ & 3,2 & 3,2 & 7,0 \\
F tratamentos & n.s. & $* *$ & $* *$ \\
R.L. & n.s. & $* *$ & $* *$ \\
R.Q. & n.s. & $* *$ & $*$ \\
\hline
\end{tabular}

n.s. $=$ não significativo $*=$ significativo a $5 \%$ de probabilidade $* *=$ significativo a $1 \%$ de probabilidade

R.L. = regressão linear $\quad$ R.Q. = regressão quadrática

Resultados semelhantes foram obtidos por Silva et al. (2006) que não observaram alterações significativas no estande final de soja em função da dessecação antecipada, com população de 250.000 plantas na média.

A massa de 100 grãos sofreu efeito significativo dos tratamentos (Tabela 2, 
Figura 1). Este parâmetro se ajustou a equação quadrática $(\mathrm{y}=-0,0149 \times 2+$ $0,2131 x+17,117)$, com aumento até o sétimo dia antes da colheita; passando este período, os grãos ficaram mais leves. Miguel (2003) obteve grãos de feijão mais pesados em função do retardamento da aplicação do herbicida dessecante, porém Silva et al.
(1999), trabalhando com os dessecantes Paraquat e Paraquat associados à Diquat em feijão, não observaram diferença na massa de 100 grãos. Silva et al. (2006) também não constataram diminuição da massa de 100 grãos de soja em função da aplicação muito antecipada de dessecantes.

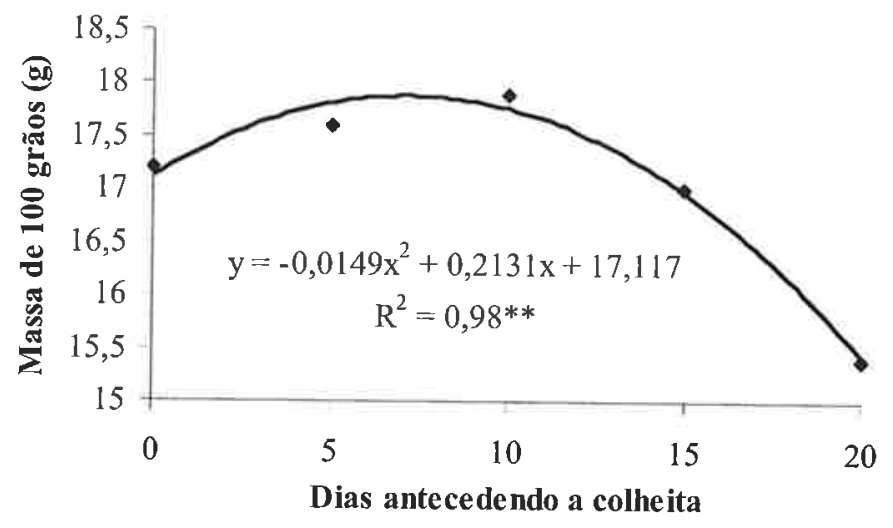

Figura 1. Massa de 100 grãos em função da aplicação de dessecante antes da colheita. São Gabriel do Oeste (MS) - 2006. ${ }^{* *}=$ significativo a $1 \%$

Ainda pela Tabela 2 observa-se efeito dos tratamentos na produtividade de grãos, se ajustando significativamente a equação quadrática $(\mathrm{y}=-1,0657 \mathrm{x} 2-13,266 \mathrm{x}+$ $3691,7)$, cujo ponto de máximo foi aproximadamente o sexto dia (Figura 2), o que mostra que dessa época até os vinte dias antecedendo a colheita, houve redução de aproximadamente $20 \%$ da produtividade, visto que quanto mais se aproximou da colheita, a translocação de fotoassimilados para semente era menor, portanto as perdas em produtividade diminuíram. Estes resultados discordam dos encontrados por Miguel (2003) que não observou diferenças na produtividade de feijão em função de épocas de aplicação de dessecantes. Porém Silva et al. (2006) notaram diferença significativa na produtividade de soja em função da antecipação da dessecação.

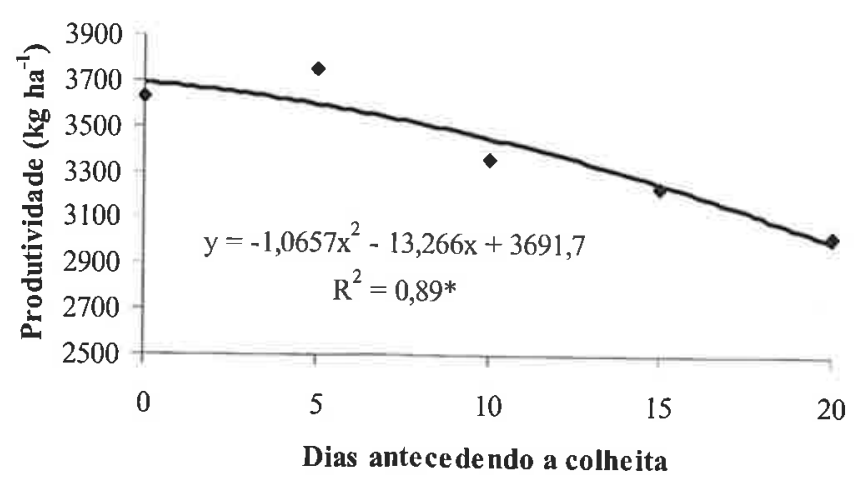

Figura 2. Produtividade de grãos em função da aplicação de dessecante antes da colheita. São Gabriel do Oeste (MS) - 2006. * = significativo a $5 \%$. 
A produtividade foi afetada, pois os grãos se tornaram mais leves em função do aumento do intervalo entre aplicação do herbicida e dessecante. Isso acontece porque ocorre redução da atividade metabólica da planta antecipadamente (Lacerda et al., 2003), mostrando que ainda ocorria translocação de fotoassimilados aos grãos, o que acarretou em menor enchimento, diminuindo assim a massa dos mesmos.

Segundo Krzyzanowski et al. (1993), reduções no rendimento ocasionadas por estresse são menores quando as sementes já acumularam quantidades consideráveis de matéria seca. De acordo com Pelegrini (1986) o aumento de tamanho dos grãos é função da quantidade de fotossintetizados disponíveis para serem translocados e da eficiência da translocação.

Pode-se observar que em todos os tratamentos a produtividade foi superior à média nacional na safra 2004/05 (2.700 kg.ha ${ }^{-1}$ ) e a média do estado do Mato Grosso do Sul da mesma época que foi de 2.680 kg.ha ${ }^{1}$ (AGRIANUAL, 2005), mostrando que mesmo com aplicação de dessecante aos 20 dias antes da colheita, onde a planta ainda está metabolicamente ativa, a produtividade alcançada (3.026 $\left.\mathrm{kg} \mathrm{ha}^{-1}\right)$ foi superior à média nacional e regional em aproximadamente $10 \%$, cerca de seis sacas.ha ${ }^{-1}$.

\section{CONCLUSÃO}

A aplicação de dessecantes deve ser realizada no máximo 6 dias antes da colheita, para não causar redução na produtividade de grãos.

\section{REFERÊNCIAS}

AGRIANUAL 2005: Anuário Estatístico da Agricultura Brasileira. São Paulo: Argos Comunicação, 2005. 498p.

AMBROSANO, E.J.; WUTKE, E.B.; BULISANI, E.A.; CANTARELLA, $\mathrm{H}$.
Feijão. In: RAIJ, B. van; CANTARELA, H.; QUAGGIO, J.A.; FURLANI, A.M.C. Recomendações de adubação e calagem para o Estado de São Paulo. $2^{\mathrm{a} e d . ~ C a m p i n a s: ~}$ IAC, p.194-195, 1997 (Boletim Técnico 100).

ARANTES, N.E.; MIRANDA, M.A.C. Melhoramento genético e cultivares de soja para o cerrado da região sudeste do Brasil. In: ARANTES, N.E., SOUZA, P.I.M. Cultura da soja nos cerrados. Piracicaba: Potafós. 1993, p.209-253.

EMPRESA BRASILEIRA DE PESQUISA AGROPECUÁRIA.

Sistema

Brasileiro de Classificação dos Solos. Rio de Janeiro: EMBRAPA/CNPSO, 1999. 41p.

EMPRESA BRASILEIRA DE PESQUISA AGROPECUÁRIA. Tecnologias de produção da soja, região Central do Brasil, 2005. Londrina: Embrapa Soja, 2005. 220p. (Sistemas de Produção, 9).

KRZYZANOWSKI, F.C.; GILIOLI, J.L.; MIRANDA, L.C. Produção de sementes nos cerrados. In: ARANTES, N.E., SOUZA, P.I.M. Cultura da soja nos cerrados. Piracicaba: Potafós. 1993, p.465-522.

LACERDA, A.L.S.; LAZARINI, E.; SÁ, M.E; VALTER FILHO, V.V. Aplicação de dessecantes na cultura de soja: antecipação da colheita e produção de sementes. Planta Daninha, Viçosa, v.19, n.3, p. 381$390,2001$.

LACERDA, A.L.S.; LAZARINI, E.; SÁ, M.E; VALTER FILHO, V.V. Aplicação de dessecantes na cultura de soja: teor de umidade nas sementes e biomassa nas plantas. Planta Daninha, Viçosa, v.21, n.3, p. 427-434, 2003.

LACERDA, A.L.S.; LAZARINI, E.; SÁ, M.E; VALTER FILHO, V.V. Efeitos da dessecação de plantas de soja no potencial fisiológico e sanitário das 
sementes. Bragantia, Campinas, v.64, n.3, p.447-457, 2005.

LAZARINI, E.; LACERDA, A.L.S.; SÁ, M.E. Avaliação do efeito da aplicação de dessecantes em diferentes épocas, na obtenção de sementes de soja de elevada qualidade fisiológica e sanitária, em Selvíria, MS. Informativo Abrates, Curitiba, v.9, n. 1/2, p.118, 1999.

MIGUEL, M.H. Herbicidas dessecantes: momento de aplicação, eficiência e influência no rendimento e na qualidade de sementes de feijão. Piracicaba, 2003. 111p. Tese (Doutorado em Fitotecnia) - Escola Superior de Ensino Luiz de Queiroz, Universidade de São Paulo.

PELEGRINI, H.F. Maturação de sementes e dessecação química do feijoeiro de inverno. Pelotas, 1986, 81p. Dissertação (Mestrado) - Universidade Federal de Pelotas.

SILVA, A.A.; DOMINGOS, M.; CARDOSO, A.A. Efeito do paraquat e da mistura paraquat + diquat como desssecantes, aplicados em diferentes épocas, no rendimento e qualidade fisiológica de sementes de feijão. Ceres, Viçosa, v.46, n.265, p.239-250, 1999.

SILVA, A.C.; FREITAS, F.C.; FERREIRA, L.R.; FREITAS, R.S. Dessecação précolheita de soja e braquiaria brizanta consorciadas com doses reduzidas de graminicidas. Pesquisa Agropecuária Brasileira, Brasília, v.41, n.1, p.37-42, 2006. 